\title{
Feeding/Swallowing Disorders: Maintaining Quality of Life in Persons with Intellectual Disability
}

\author{
Luis F. Riquelme ${ }^{1,2,{ }^{*} \text {, Rebecca D. Benjamin }}{ }^{1,2}$, Hannah J. Tahhan ${ }^{1,2}$, \\ Gracelynn K. Sandoval $^{1,2}$, Naga Alomari ${ }^{1,2}$ and Alexandra Soyfer ${ }^{1,2}$ \\ ${ }^{1}$ Department of Speech-Language Pathology, New York Medical College, Valhalla, NY, USA \\ ${ }^{2}$ Barrique SLP@Center for Swallowing and Speech-Language Pathology, New York Methodist Hospital, \\ Brooklyn, NY, USA
}

\begin{abstract}
Persons with intellectual disability (ID) have received little attention in systematic studies of healthcare and quality of life. Less attention has been provided to specific disorders, such as those impacting the swallowing mechanism. In comparison to the general population, persons with ID experience noticeably greater healthcare inequalities and despite greater life expectancy, it is still lower than the general population. This paper serves as an introduction to healthcare colleagues regarding the risks involved in choking and swallowing disorders in persons with ID, how to evaluate these potential risks and possible treatments. Associated etiologies are presented. A discussion on feeding disorders versus swallowing disorders is also introduced. The inadequacy of swallowing assessment services to persons with ID may be related to the lack of professionals with specialized training in working with this population, reduced funding for research to explore options for improved nutrition and reduced risk of choking and minimal research on changes in feeding skills and/or swallow physiology in this select group of individuals
\end{abstract}

Keywords: Dysphagia, Feeding disorders, Aspiration, Videofluoroscopy, Endoscopy.

\section{INTRODUCTION}

Persons with intellectual disability (ID) have received little attention in systematic studies of healthcare and quality of life. Less attention has been provided to specific disorders, such as those impacting the swallowing mechanism. In comparison to the general population, persons with ID experience noticeably greater healthcare inequalities and despite greater life expectancy, it is still lower than the general population [1].

Incidence rates of persons with ID vary by country and study being reviewed. Most studies report on incidence in children and not adults. This is often due to the mandatory tracking of children with disabilities conducted by health service administrations in many countries around the world. Tracking adults with ID varies by country, and sometimes by region. In Finland, for example, Heikura et al. [2] found that the cumulative incidence of mental retardation of any severity was 12.6/1000. Others reported that the incidence varied from $5.5 / 1000$ for mild mental retardation to $7.4 / 1000$ for moderate-severe mental retardation [3]. In the United States, the cumulative incidence has been reported at 9.1/1000 [4,5].

In this population, dysphagia has rarely been investigated, despite its impact on quality of life. The

*Address correspondence to this author at the Department of SpeechLanguage Pathology, New York Medical College, Valhalla, NY, USA;

Tel: (917) 216-1340; Fax: (718) 780-7802; E-mail: luisslp@aol.com prevalence of swallowing disorders (dysphagia) is unknown. As cited in Chadwick \& Jolliffe [6], several studies indicate that the numbers may be as high as $49 \%$ in the population over 50 years of age in the United States. In 1989, Sheppard \& Hochman, as cited in Sheppard, 2006, reported that the prevalence of dysphagia increased with the severity of physical disability [7]. While it is a symptom of many diseases, dysphagia is poorly understood and often under diagnosed. To date, only one published study has attempted to categorize dysphagia by stages in persons with ID. Namely, Hardwick 1993 [8], in her unpublished dissertation reported that of 142 adults with ID, $70 \%$ presented with oral stage dysphagia, $82 \%$ with pharyngeal stage dysphagia and $55 \%$ with esophageal stage dysphagia [6]. The original source was not located, and so questions regarding how participants were evaluated and placed in these categories remain unanswered. The impact of dysphagia has implications for health, safety and general well-being. An additional complicating factor in tracking dysphagia incidence in persons with ID is its definition. In many situations, the prevalent intake problem of the patient is related to feeding; in other situations it's related to only the oral stage of swallowing (e.g., chewing); and yet in others to pharyngeal dysphagia, where the problem may be related to a myriad of concurrent neurological etiologies and possibly lead to aspiration or choking episodes. Of note in all situations is the impact of behavior and attention on the ability to successfully transport a bolus 
(i.e., food or liquid) from the oral cavity (mouth), through the pharynx (throat) and into the esophagus, to successfully arrive in the gastric pouch (stomach).

Over the past several decades, better health and social care for persons with ID has led to their improved life expectancy, which now approaches that of the general population [9]. As a consequence, people with ID will experience many of the same agerelated chronic health conditions, life events, and functional decline that are frequently observed in the general aging population.

Dysphagia, or swallowing disorder, is also referred to as an impairment in deglutition. Dysphagia is a symptom of an underlying disease/disorders process, which may be neurogenic, mechanical or psychiatric in nature. These would result in physiologic changes in the transport of the bolus from oral cavity (mouth) to the gastric pouch (stomach). Feeding disorders may also accompany or exacerbate problems with swallowing or swallowing safety. These would involve transfer of the bolus from the plate to the oral cavity and its management (e.g., rate of intake, size of bolus, among others). The differentiation of a feeding disorder from a swallowing disorder is even less understood in this population.

Choking is said to be prevalent in this population, but no systematic review has investigated the reason. Choking at mealtime may be a result of overstuffing the oral cavity, rapid rate of intake, reduced attention during feeding, difficulty coordinating the different physiological events that take place for successful bolus transfer to the stomach or delayed pharyngeal swallow, among others. Basically, it involves the bolus, liquid or solid, entering the upper airway and blocking it, resulting in a choking/coughing episode. This is a typical physiological response in attempts to clear the airway, and may result in death if not attended to immediately.

The speech-language pathologist is one of the members of a comprehensive feeding/dysphagia team. Other members typically include professionals from occupational therapy, nursing, gastroenterology, otolaryngology (ENT), neurology and clinical nutrition. In most settings providing services to persons with ID, minimal services from speech-language pathology, occupational therapy and medicine are available. Most available is nursing. Despite the presence of these professionals, it should be understood that not all are trained in the specialized area of feeding/dysphagia evaluation and treatment. For example, in the field of speech-language pathology, this is a specialized practice area. The collaboration amongst all professionals with specialization in feeding/dysphagia is essential, so as to ensure proper identification of the problem and its etiology. In the experience of these authors, the clinical and instrumental assessments are often insufficient, without information on overall mealtime management. This is often essential to determining how the environment impacts intake and bolus transfer safety. Informally, we have not identified a direct correlation between cognitive status and feeding/dysphagia efficiency. Namely, some persons with severe ID may swallow without any difficulties, while others with mild ID may present with a variety of feeding/swallowing difficulties.

\section{FEEDING DISORDERS VERSUS DYSPHAGIA}

Persons with Intellectual Disability (ID) face difficulties at mealtime throughout their lifespan, ranging from minimal to significant. In some instances, a feeding disorder and a swallowing disorder (dysphagia) may go hand-in-hand and cause mealtimes to be very challenging. In other instances, these two disorders remain separate and so it is important to be able to delineate what signs and symptoms are attributed to either a feeding disorder or a dysphagia.

\section{Feeding Disorders}

According to Arvedson 2008 [10], feeding disorders include a broad range of eating activities that may or may not be accompanied by difficulty swallowing food or liquid. In adults, it is typically defined as difficulty in transporting the food from the plate to the oral cavity. However, other behaviors may also be classified as feeding disorders. These include food refusal, disruptive mealtime, extreme selectivity in food preferences, high risk for failure to thrive or less than optimal growth and/or the absence of self-feeding skills [10]. In typically developing children, the incidence of feeding disorders ranges from $25-45 \%$ and has been reported to be as high as $80 \%$ in children with developmental disabilities [11]. Many of the children with ID may continue to face these challenges as adults. Much difficulty exits in obtaining information on feeding disorders in persons with ID as the initial diagnosis of ID may change with age, or vice versa. Additionally, the feeding skills of some persons with cerebral palsy or Down syndrome, for example, may regress after a change in medical status, which then 
necessitates a revision of the initial plan for feeding therapy.

Developmental readiness is essential in order to advance to a more complex level of eating and drinking. Because of the known developmental delays evident in persons with ID, many crucial feeding milestones may be missed and therefore cause the resulting feeding disorders. At 6 months of age, typically developing babies exhibit the motor control necessary to sit up and maintain head support for the introduction of spoon-feeding. A child with a developmental disorder may present with delayed motor development, thus causing the introduction of spoon-feeding to take place much later in infancy or even when a toddler. Very often, the child develops strategies to compensate for hypotonia and decreased oromotor organization. This may be evident in motor tasks such as spoon stripping. When this window of opportunity for the development of oral musculature surpasses the child, as per the literature on neuroplasticity, it's then possible that if you "don't use it, you lose it" [12]. As the child matures, more solid consistencies are presented. This requires skills such as lingual lateralization of the bolus, buccal tension coupled with labial closure during chewing and swallowing for liquids, and bolus propulsion via the tongue. At 9 to 12 months of age, typically developing children tolerate a variety of foods. A child with ID will take longer to reach these milestones and may eventually develop food refusal, if not managed properly. Moving to higher textures and consistencies will prove to be challenging and often results in many adults with ID needing modified diets. Essentially, this proves the need for a developmental approach to the attainment of feeding skills in children with ID. These services are not always available, or sought, by the medical care team. As children reach their first birthday, self-feeding skills are emerging as the age of independence leads to table foods. Chewing becomes more refined, per the presence of more teeth [13]. Moreover, many persons with ID demonstrate difficulties in self-feeding. One of the more common behaviors is overstuffing the oral cavity during mealtimes. This is often related to impulsivity, resulting in rapid rate of intake and reduced attention. This is problematic, as it causes persons with ID to fill their mouths to the maximum in the presence of poor advanced chewing skills. Often times, choking is a common complaint, which can be a result of overstuffing, and not a physiological dysfunction of airway protection during the swallow process. Because the oral cavity is filled to the maximum, part of the bolus may prematurely dump in the pharyngeal recesses (valleculae and/or pyriform sinuses) and be misdirected into the airway, causing the choking episode.

\section{Dysphagia}

Dysphagia, or swallowing disorder, is defined as difficulties in one or more of the phases of swallowing which include the oral preparatory phase, oral phase, pharyngeal phase, and esophageal phase [10]. This may or may not lead to penetration, aspiration, or silent aspiration. As described in Riquelme et al., 2008 [14], each stage is independent and must be carefully assessed to fully understand a swallowing disorder. The oral stage involves lip closure, mandibular (jaw) movement, buccal (cheek) tension, lingual range of motion (ROM) and anterior velar (soft palate) movement. During this stage, the food or drink is mixed with saliva forming the bolus. This takes place in the anterior oral cavity. Once formed, the bolus is propelled posteriorly by the tongue raising and gliding it to the posterior oral cavity. At this point, the pharyngeal swallow response is elicited. This region is rich in sensory receptors for taste, temperature, taste and volume of the bolus. Once the swallow is triggered, the pharyngeal stage commences. This stage involves closure of the velopharyngeal port (entry to nasal cavity), pharyngeal contraction (to squeeze the bolus inferiorly, toward the esophagus), base of tongue excursion (to help push the bolus inferiorly), airway protection and upper esophageal sphincter (UES) relaxation. Airway protection is achieved by four mechanisms that close the upper airway: vocal fold adduction (closure), false vocal fold adduction, epiglottic inversion and upward movement of the laryngeal (upper airway) mechanism. This action helps relax the UES for bolus passage.

Relevant to this population is the fact that the gag reflex is not associated with swallow function, as the neural pathways for each are different $[15,16]$. Secondly, the swallow is no longer considered purely a reflex. The act of swallowing is partly reflexive, as per the notion of a central pattern generator keeping all actions in order, the swallow is also modulated by taste, temperature, texture and volume. Hence, changes in swallow pressures and efficiency ensue related to bolus characteristics.

In some cases, choking episodes become more and more frequent, and persons with ID may be diagnosed 
with dysphagia, even in the absence of a full diagnostic work-up. In a study completed by Calis et al., 2008 [17], dysphagia was investigated in children with cerebral palsy and ID. For their study, examiners used the Dysphagia Disorders Scale (DDS), as developed by Sheppard in 2002, in order to evaluate the presence, characteristics and severity of dysphagia. Of the participating 194 children, $76 \%$ presented with moderate to severe dysphagia and $15 \%$ presented with profound dysphagia. From these results, dysphagia was positively correlated with increased motoric impairment. Of note, "parents' opinions on the presence of dysphagia did not correlate with the actual presence of clinical features of dysphagia as assessed by a standardized mealtime observation" [17].

In certain cases, differentiating feeding disorders from dysphagia is quite the challenge for the examiner. For some patients, these two coexist and as a result, one can be a subsequent result of the other, or vice versa. A skilled examiner, often a speech-language pathologist, will be able to tease out what signs and symptoms are attributed to feeding difficulties and which are a result of a more physiologic breakdown, or a swallowing difficulty. This may require additional collaboration with the occupational therapist. As previously mentioned, because much disruption may be seen in self-feeding skills, this could result in a breakdown of the physiologic integrity of the swallow mechanism. The examiner must therefore use his/her "magnifying glass" to solve the case and therefore, put that feeding/swallowing disorder "behind bars". By putting the pieces of the puzzle together, persons with ID will benefit from improved quality of life, and caregivers will become educated and empowered with the knowledge they receive from the clinical team providing assessment, treatment, counseling and education.

\section{ASSOCIATED ETIOLOGIES}

\section{Aspiration}

The discussion of dysphagia management for persons with ID must include aspiration and aspiration pneumonia as two primary concerns. Aspiration is defined as the entry of food or liquid into the airway below the level of the vocal folds [18]. An aspiration event does not always result in aspiration pneumonia. Aspiration pneumonia is a respiratory infection that is the result of colonization of bacteria in the lower respiratory tract. The term aspiration pneumonia is often used to describe the development of pneumonia in the setting of other risk factors for oropharyngeal dysphagia [19]. This is relevant, when we consider the fact that individuals who aspirate may or may not develop aspiration pneumonia. A classic study conducted by Langmore et al., 1998 [20], reported that many factors contribute to the development of aspiration pneumonia, outside of aspiration itself. They highlighted that in order for aspiration pneumonia to ensue, the aspirated material must be pathogenic to the lungs. Factors associated with increased bacteria colonization included, functional dependence status, oral/dental care and reduced salivary flow. This is of interest as nearly half of all healthy adults aspirate a small amount of secretions in their sleep [21, 22, 23]. Although concerning, many of the bacterial risk factors are treatable with the implementation of good oral hygiene and care. It should also be highlighted that Langmore and her team found that the presence of dysphagia alone was not a significant predictor in the development of pneumonia. This is not to say that aspiration resulting from dysphagia is not a concern, but that it requires other factors to be present for there to be significant risk involved. This further lends to the holistic approach for treating and managing patients with significant predictors for aspiration pneumonia, including persons with ID.

Given that there is little data on the incidence and prevalence of aspiration pneumonia in the ID population, we must look to research conducted with an older demographic to determine possible risk factors for this population. It has been shown that aspiration is the number two most common occurring infection seen in the elderly population living in nursing homes and accounts for $13 \%$ to $48 \%$ of all infections treated. This is of concern as aspiration pneumonia contributes anywhere from $20 \%$ to $50 \%$ to the mortality rate, and in some cases up to $80 \%[20,24,25,26]$. In a literature review on aspiration pneumonia and dysphagia in the elderly, reported by Marik \& Kaplan [23], the authors identified the following risk factors associated with an increased incidence of aspiration pneumonia: the presence of dysphagia secondary to a cerebrovascular accident or other neurological impairment, volume of aspirate, baseline pulmonary health, decreased laryngeal sensation, absence of the cough reflex and nutritional status and its effects on the immune system. Given the aforementioned are common in the elderly population, the incidence of pneumonia is six times higher in those 75-years and older, as compared to those younger than 60 -years of age $[23,27,28,29$, 30]. Although there is no direct correlation between 
young adults with ID and the aging population, it is important to consider these risks as many persons with ID may demonstrate these characteristics, in addition to the fact that, as mentioned earlier, life expectancy in persons with ID is increasing.

Aspiration may be prandial or non-prandial. Prandial aspiration is when material enters the airway at the time of ingestion, as in during the swallowing process. Non-prandial aspiration is the result of material entering the airway after the act of swallowing has been completed, as in the case of regurgitated material entering the airway. Prandial aspiration is most commonly associated with signs and symptoms of dysphagia at mealtimes, such as coughing, choking, throat clearing and/or wet/gurgly vocal quality. Nonprandial aspiration is typically seen in individuals with esophageal impairment and/or reflux, and occurs when regurgitated material passes back through the upper esophageal sphincter and into the pharynx and airway. Clinically identified signs and symptoms of non-prandial aspiration may include: no overt signs and symptoms of dysphagia at mealtime, cough after meal is completed, complaint of food getting "stuck" after the meal (usually not during), sore throat, aversion to oral (PO) intake, history of recurrent aspiration pneumonia and history of gastroesophageal reflux disease (GERD). When non-prandial aspiration occurs, the associated chemical injury is referred to as aspiration pneumonitis [19].

Gastroesophageal reflux disease (GERD) is one of the most common health problems found in persons with ID that is directly linked to aspiration and aspiration pneumonitis [31]. It is generally associated with dysfunction of the lower esophagus. When improperly managed and severe enough, it can result in microaspiration of gastric contents into the lungs. This microaspiration over time causes a chemical burn of the tracheobronchial tree and pulmonary parenchyma, resulting in a severe parenchymal inflammatory reaction that can increase the risk of infection [19]. Langmore and colleagues [20] found that GERD was one of the highest associated health factors associated with aspiration pneumonia, especially when in conjunction with chronic obstructive pulmonary disease (COPD), contributing nearly $50 \%$ to the incidence rate. In addition, reduced esophageal motility in the absence of GERD was also found to be a significant predictor of pneumonia. According to May \& Kennedy [31], and their work related to health and problem behaviors among persons with ID, in the presence of severe intellectual impairment, GERD along with other health impairments may be misdiagnosed as a behavioral disturbance, or undiagnosed entirely. Furthermore, undiagnosed and untreated health impairments may reduce the life expectancy and/or contribute to secondary health complications. These findings draw attention to the need for careful management of esophageal dysfunction in persons with ID, further emphasizing the importance of a holistic approach to dysphagia management for persons with ID.

\section{Rumination Syndrome}

Similar to GERD and reduced esophageal motility, another characteristic of dysphagia seen in persons with ID is eructation or voluntary regurgitation of material, sometimes referred to as rumination syndrome. In clinical practice, these authors have noted that some individuals with ID tend to gag, or as some caregivers perceive, "choke" on food during meals. However, during videofluoroscopic examination, the patient is found to voluntarily elicit a gag reflex or regurgitate the bolus back into the pharynx or oral cavity. Rumination has been found to occur in $6-10 \%$ of persons with ID who are institutionalized. This behavior is suspected to be a type of self-stimulation, as no other upper esophageal dysfunction is observed and the action is repetitive and stereotypical in nature. Albeit somewhat benign, this behavior is of note as it can result in overflow into the upper airway and subsequent aspiration [32].

\section{Polypharmacy}

It is also noteworthy to consider the effects of polypharmacy on swallowing in persons with ID. Polypharmacy is considered to be the concurrent use of multiple psychotropic and non-psychotropic drugs $[33,34,35]$. In a literature review conducted by Stortz, Lake, Cobiga, Ouellette-Kuntz, \& Lunsky, 2014 [33], the authors reported that persons with ID receive an increased amount of prescriptions per year as compared to the general population $[33,36]$, with the incidence of polypharmacy in the ID population ranging between $11 \%$ to as high as $60 \%$ depending on methodology employed [33, 37-45], thus concluding that polypharmacy puts persons with ID at a higher risk for associated side effects. It should also be considered that persons with ID often demonstrate increased difficulty understanding and reporting associated side effects of medications [33, 46-50], which puts persons with ID at greater risk for medication non-adherence, adverse drug reactions, and drug-drug interactions [33, 
$35,36,41,51,52,53]$. Other risks associated with polypharmacy in this population include, increased hospitalizations [33, 54], falls [33,55], and increased risk of mortality [33, 53]. Of note in their literature review, Stortz et al., [33], found that the definition of polypharmacy varied between the ID and elderly populations, with literature related to the ID demographic reporting findings based on use of two or more psychotropic drugs, and the literature on the elderly population reporting data on the use of five or more, nine or more, and even ten or more medications, for both psychotropic and non-psychotropic. This, as the authors later reported, was one of the most significant limitations of their review, as there was little consistency in the literature regarding the number of drugs prescribed, as well as, the time in which the drugs were prescribed.

Given that persons with ID are more likely to be prescribed multiple medications beginning at an early age [56], they are also more likely to experience the following side effects associated with changes in oropharyngeal swallow function: changes in smooth muscle, increased risk of movement disorders, xerostomia (dry mouth), depression of the central nervous system (CNS) and esophageal injury [56]. Specifically, risk of xerostomia is associated with thirtyone commonly prescribed drugs [56], with 12 of those being antipsychotic/neuroleptic medications. This is of note as usage of these medications is estimated to be between $28 \%$ and $89 \%$ for persons with ID [33, 37, 38, $40,58,59,60]$. Xerostomia is of concern as bolus formation and cohesion is dependent on production of an adequate amount of saliva. Without adequate bolus formation, persons with ID are at a greater risk for premature spillage to the pharynx and/or discoordination of the swallow. In addition, polypharmacy may also result in changes in levels of alertness. These physiological changes in conjunction with changes in alertness, can significantly increase a person's risk of aspiration over time. This is important, as simple changes in an individual's pharmacological management can significantly change their risk for aspiration, or difficulties during meals, over time.

Furthermore, the discussion of the effects of polypharmacy on swallowing is critical as we consider and manage this population across the lifespan. As medical and social management of this population advances, the lifespan of persons with ID has increased drastically. Given the elderly are more at risk for side effects of polypharmacy, and persons with ID are likely to be prescribed multiple medications at an early age [57], we must consider these factors in conjunction with risk factors associated with normal aging, such as, sarcopenia, and changes in sensorymotor acuity [61] All of which have been found to be associated with presbyphagia in healthy adults. In combination, the aforementioned can subsequently have an effect on base of tongue movement, pharyngeal contraction, hyolaryngeal (upper airway) excursion and upper esophageal sphincter opening, which can result in increased amounts of residue and risk for aspiration. Once again, this data serves reiterate the importance of a holistic approach to polypharmaceutical management for persons with ID.

\section{THE EVALUATION PROCESS: CLINICAL}

A clinical swallow evaluation (CSE) by a skilled dysphagia clinician is essential for maintaining safety of eating by mouth for persons with ID and dysphagia. In many states, persons with ID attending day treatment centers or living in group homes are expected to undergo a dysphagia evaluation once per year. Other times, persons with ID will undergo an evaluation as a result of a choking incident or ongoing observations of suspected dysphagia by staff. According to Carnaby, 2012 [62], the clinical swallowing assessment "provides an estimate of swallowing ability (as opposed to disability) of the patient. This information becomes critical in directing further actions and estimating prognosis." At present, there is no consensus on a standardized assessment protocol for dysphagia; furthermore, it is unclear whether a dysphagia assessment should include a clinical evaluation, instrumental assessment or both.

Controversy exists as to the reliance of a CSE, as per a variety of data that questions its sensitivity and specificity [63]. Of note in reviewing this data is that all studies published that address the relationship of CSE to an instrumental examination only focus on a few features from the CSE and correlate it with presence or absence of aspiration. This is limiting, as symptomatology that leads to dysphagia is more than aspiration, per the complexity of swallow physiology. In addition, most of this research has been completed with patients post-stroke, and none with persons with ID. Many clinicians accept the fact that the CSE does not provide information on presence or absence of aspiration, nor does it accurately represent the biomechanics of the swallow in the patient, however, they employ it for other reasons. Rationales for use of the CSE range from reduced access to instrumental examinations to the need to create a hypothesis of the 
problem prior to further testing [64]. The preference of our team is to conduct a CSE so as to obtain all pertinent history, address the person's complaint and evaluate any additional factors that may influence swallow physiology. In some situations, we are able to differentiate a true physiological problem from a behavioral difference. This is of great significance when working with persons with ID.

There is not complete agreement on the components of the CSE. Mathers-Schmidt et al., 2003 [65], noted that among speech-language pathologists surveyed, there was agreement on 11/19 items for the examination. For the most part, a good CSE includes: background history, cognitive-linguistic screen, an oral mechanism/cranial nerve examination, a speech/voice assessment and, as appropriate, trials of food per mouth (PO). This clinical examination should not be confused with a "dysphagia screening," which is designed as a minimally invasive and quick procedure to be administered by a variety of healthcare professionals and is usually reported as pass/fail.

The CSE begins with gathering background information; the clinician must obtain a detailed history from the medical information provided, from the referring physician or nurse and from the person with ID and/or the accompanying healthcare aide. Important questions to include are: Why is the person referred for a swallowing evaluation? What is their current diet? Are there overt signs/symptoms of aspiration or difficulty swallowing? Does the person require 1:1 supervision at meals? Has the person had any recent hospitalizations? If so, for what admitting diagnosis? Does the person have a history of respiratory infections or pneumonia? Has the patient lost significant amount of weight over the past six months? Any other concerns?

Once a thorough history is obtained, a hypothesis may be in the making, and a brief cognitive-linguistic assessment, including orientation questions and ability to follow commands, is required. This brief screening will guide the examiner, most often a speech-language pathologist, when treatment and/or other recommendations are made. For example, it is important to determine if person with ID may be able to follow compensatory strategies, based on results of the swallowing assessment (clinical or instrumental). Some feeding strategies require awareness of the deficit and ability to recall recommendations at meal times.

An oral mechanism/cranial nerve examination is essential in determining if there is an underlying neurological pathology or mechanical deficit causing the dysphagia complaint. As has been mentioned throughout this paper, a person with ID may also develop progressive neurological disorders as he/she ages. For example, a 68 year-old male with ID may also be diagnosed with Parkinson Disease. This latter diagnosis presents with a high incidence of dysphagia. The oral exam needs to be performed to determine strength, coordination and range of motion of the lips, mandible, tongue and soft palate (velum); as well as examine the intraoral structures for sensorium, mucosa and dental status. Performing this exam on an uncooperative person or a person unable to follow commands may be challenging. In this case, the skilled examiner may conduct an observation of the oromotor structures during a variety of speech and swallowing tasks. This may suffice to determine the overall competence of these structures.

Voice is another aspect to be investigated during the CSE. Vocal quality may be determined perceptually based on clinical expertise. Vocal quality is usually described as hoarse, harsh, breathy, hyponasal, hypernasal or strained/strangled. Specifically, hoarseness, whispering, nasal speech and complaint of regurgitation of liquids through nose are indicators of specific cranial nerve dysfunction [62]. Vocal intensity, or volume, can be assessed with a sound level meter or perceptually. Infrequently, an instrumental acoustic assessment of voice (i.e., VisiPitch or other voice instrumentation) is employed with this population. Dysphonia, or voice disorder, can be an indicator of vocal fold or general laryngeal dysfunction, an important mechanism for airway protection during swallowing.

The CSE performed in an outpatient setting often includes PO (per oral) trials. The consistencies presented should be determined by the person's current diet and dysphagia complaint. The examiner may administer the trials, or allow the person to feed $\mathrm{him} /$ herself. This allows the examiner to rule-out any potential problems with self-feeding, such as rapid rate of intake or poor determination of bolus size. During PO administration, the examiner will observe the oral stage, which includes lip closure, buccal/cheek tension and mandibular range of motion (for chewing). Laryngeal palpation during swallow will determine presence/absence of a swallow, but will not provide information regarding the adequacy of airway protection via hyolaryngeal excursion or other pharyngeal components of bolus flow. After the swallow, the examiner will visualize the oral cavity to 
assess for any inappropriate amount of oral residue, and will observe for a cough, throat clear, a period of shortness of breath or any signs of distress. If the person has specific feeding tools that are used at all meals, these should be included during the CSE (i.e. modified spoons, straws, "sippy" cups, etc.). For example, it is purposeless to assess liquids via cup if the person only drinks liquids via straw. As close to a "real-world" assessment the examiner can manipulate in an outpatient clinic setting will prove to be more beneficial and meaningful to the patient and their swallowing safety. A CSE is but a moment in time; a person with ID likely eats three meals per day, so the ability to generalize information from three trials of each consistency is difficult. The examiner should control for as many factors as they can while outside of the person's typical environment (i.e., positioning, feeding devices and desired PO consistencies).

Following the results of the CSE, the examiner will determine if the person needs further instrumental assessment. Information gathered during the clinical swallow evaluation will guide these decisions. According to Coyle, 2015, "Omission of a thorough clinical evaluation before instrumental testing of swallowing reduces the value of diagnostic imaging test to that of an expensive pass-fail screen," meaning the components of information gathered during the clinical assessment are essential to determining diagnostic impressions [66].

\section{THE EVALUATION PROCESS: INSTRUMENTAL}

The two most commonly used instrumental tests are the Videofluoroscopic Swallow Study (VFSS) and the Fiberoptic Endoscopic Examination of Swallowing (FEES). Other less frequently utilized instrumental assessments include scintigraphy and pharyngeal or esophageal manometry, to evaluate coordination and contraction of muscle groups. The types of food and liquid consistencies tested during VFSS and FEES will again be determined on a person by person basis.

The VFSS or Modified Barium Swallow (MBS) is considered by many the gold standard in dysphagia assessment. This examination is performed collaboratively by the speech-language pathologist and the radiologist. For this exam, the patient is seated in a chair and is fed barium impregnated liquids and solids of various consistencies. The patient's swallowing mechanism is visualized with the assistance of an x-ray and is recorded for interpretation. This type of evaluation allows the speech-language pathologist to examine all stages of swallow in real time, as well as the efficacy of appropriate compensatory strategies.

FEES is the other commonly used instrumental assessment. It involves passing the nasoendoscope through the nares into the hypopharynx. The examiner is able to assess vocal fold function and secretions/food management before and after the pharyngeal swallow. Foods and liquids with/without coloring are utilized for the visualization of bolus transport and residue assessment.

In comparison, the VFSS is a great tool that allows the examiner to visualize all four stages of the swallow, as well as aspiration if it occurs. However, VFSS requires exposure to radiation and requires the use of barium, which may alter food taste and consistency. FEES is an instrumental exam that permits assessment of saliva management in addition to food. It is easily performed at bedside and can be extended to evaluate endurance during meals. However, FEES requires the use of a nasoendoscope, which may be uncomfortable or even unbearable to some patients. This test also limits the evaluation of stages of swallow to primarily pharyngeal stage only, because the scope bypasses the oral cavity.

The types of food and liquid consistencies tested during VFSS and FEES will again be determined on a patient by patient basis. Information gathered during the CSE will guide these decisions.

Following the interpretation of the instrumental test, a report should follow by the examiner, most often the speech-language pathologist. A report that is clear and thorough will ensure proper decision-making by the team caring for the person with ID. A complete evaluation report must include: number of $\mathrm{PO}$ trials for each consistency, when, why, and with what consistency did penetration and/or aspiration occur, patient's response to penetration/aspiration and any compensatory strategies trialed during the study and their success or failure. In the case where a person does not undergo instrumental assessment, the CSE report must indicate why further testing is not indicated at this time; including but not limited to, no overt clinical signs or symptoms of dysphagia, tolerating PO diet, probable behavioral/feeding signs that contribute to difficulty at mealtime or no recent hospitalizations. For persons with ID, recommendations should also be thorough and include number and type of PO trials administered during the clinical assessment and their outcomes. Recommendations should include food and 
liquid consistency, strategies required/suggested and safe eating/feeding recommendations. Riquelme, 2015, suggested that the examiner conducting a CSE must be aware of its utility, as well as its limitations [64]. This is in line with the information presented above.

\section{TREATMENT OVERVIEW FOR FEEDING/ SWALLOWING DISORDERS (DYSPHAGIA)}

Treatment approaches for persons with ID should focus specifically on the individual's behaviors and any pathophysiology identified during testing for dysphagia. This may also include providing assistance during meals to remind and ensure the patient follows safe swallowing strategies, such as: sitting upright, small bites/"sips", and taking breaks during the meal.

\section{Treatment: Feeding}

Feeding disorders in adults with ID may be the result of residual patterns from childhood or selfderived compensations for problems that have arisen as adults, as mentioned previously. Individuals may present aversion behaviors to food, or more specifically, certain textures. This may be due to a variety of factors: tactile defensiveness, discomfort related to GERD, or no/reduced appetite. As per the higher incidence of GERD in this population, a referral to a gastroenterologist may be warranted. Patients may also demonstrate impulsivity during meals, which may lead to reduced airway protection.

It is important to monitor and ensure that the person with ID is consuming an adequate amount of PO. Appetite stimulants or supplements, in addition to meals may be recommended to ensure adequate nutrition/hydration. Patel and Hillier, 2013, found that Mirtazapine, which has been used as an appetite stimulant for the elderly, also increased appetite in a case series of three individuals with ID eliminating the need for a percutaneous endoscopic gastrostomy (PEG) [67].

On the other hand, if an individual has undergone feeding tube placement (most often a PEG), and has been cleared to consume food/liquids by mouth, or demonstrates reduced or no PO intake, then initiating a PEG weaning protocol may be helpful. PO will be introduced slowly, for example, starting with a lunch tray. In this scenario, it is important to discontinue tube feedings at least two hours prior to the meal, so as to ensure emptying of the stomach, presence of hunger and avoid reflux. Having a PO/TF (tube feed) schedule will be important in ensuring hunger satiation and will likely increase PO intake. It is important for physicians, nurses, and dieticians to work together to monitor the amount of $\mathrm{PO}$ a person is consuming and reduce the amount of tube feedings accordingly. Once the person is consuming an adequate amount of nutrition/ hydration by mouth, then the tube feedings can be discontinued and the PEG removed.

\section{Treatment: Swallowing}

Persons with ID may also demonstrate signs and symptoms of oropharyngeal dysphagia that is more directed to changes in swallow physiology and may result in misdirected or difficult bolus flow. In a descriptive analysis of 101 adults with ID, Chadwick \& Jolliffe, 2009 [6], found that $94 \%$ demonstrated an oral stage dysphagia, $51 \%$ presented with a pharyngeal stage dysphagia, and $34 \%$ demonstrated an oropharyngeal dysphagia during a clinical evaluation and/or videofluoroscopic swallow study. On the CSE, the speech-language pathologist may observe oral stage deficits such as: anterior loss of bolus or delayed anterior-posterior transport, and suspect pharyngeal deficits secondary to observing coughing or wet/vocal quality during PO trials. During the videofluoroscopy, the examiner may note oral stage dysphagia characterized by: anterior spillage, poor bolus formation, (which may be due to reduced lingual movement/poor tongue control) reduced mastication skills (i.e. chewing by moving the jaw up and down instead of a rotary movement), reduced base of tongue retraction, and/or premature spillage/dumping to the pharynx. Characteristics of a pharyngeal stage dysphagia include: penetration and/or aspiration before, during, or after the swallow, reduced hyolaryngeal excursion, no/incomplete epiglottic retroflexion and/or reduced pharyngeal contraction. Depending on the cognitive ability of the individual, the examiner may trial compensatory strategies to improve airway protection.

Based on the clinical examination and/or instrumental exam, the SLP will introduce a patientspecific treatment plan. The goal is for the patient to safely consume the least restrictive diet by mouth resulting in the maintenance of proper nutrition. Recommendations may include altering the diet consistency, using compensatory strategies and/or direct therapy to improve strength or coordination of the oropharyngeal structures.

\section{Diet Types}

Recommendations regarding the least restrictive diet type usually requires the collaboration of the dietitian with the SLP. Specific diet consistencies, or 
textures, and their names vary by facility. The least restrictive diet is usually known as regular, followed by chopped/mechanical soft, then puree and lastly, blenderized. Again, each facility may substitute these names with others, such as easy to chew, spoon thick, etc. A similar problem is noted with liquids, however, to a lesser degree. Most recently, a group of professionals from varied fields joined to form the International Dysphagia Diet Standardisation Initiative (IDDSI). The group aims to develop standardized terminology and definitions for texture modified foods and thickened liquids for individuals with dysphagia of all ages, in all care settings and all cultures (www.iddsi.org). In 2013, Cichero et al. published a paper on the need for international terminology for texture modified foods and thickened liquids [68]. The paper served to highlight this need across the globe and across all settings, as well as presented a plan for doing so.
Of note, we believe that thickened liquids should only be recommended after an instrumental examination.

\section{Compensatory Strategies}

Some common compensatory strategies that may facilitate safe swallowing and reduce risk of aspiration may include:

- $\quad$ Sit upright when eating/drinking (Sitting in a reclined position increases the risk of aspiration).

- $\quad$ Small bites/sips (A sippy cup may be helpful for individuals who need small/isolated "sips"). Butler, Stuart, Leng, Rees, Williamson, and Kritchevsky [69] found that a smaller bolus size improved airway protection in healthy adults.

- $\quad$ Eat slowly, allowing breaks between bites/sips (This is helpful for individuals who may fatigue during meals).

Table 1: Commonly Used Food Descriptions in the United States

\begin{tabular}{|c|c|}
\hline $\begin{array}{l}\text { - } \frac{\text { Puree Consistency: Food is blended to the consistency of }}{\text { apple sauce/pudding }} \\
\text { - } \quad \text { Chopped Consistency: Food is cut up into small pieces } \\
\text { - } \frac{\text { Soft Consistency: Food is easier to chew compared to }}{\text { regular, i.e. meat is cooked longer, extra sauce/gravy }} \\
\text { - } \quad \text { Regular Consistency: Solid food with no alteration }\end{array}$ & $\begin{array}{l}\text { - } \quad \text { Thin: regular liquids, such as water } \\
\text { - } \quad \frac{\text { Nectar-thick liquids: liquids thickened to a nectar-thick }}{\text { consistency (e.g., thick shake) }} \\
\text { - } \quad \frac{\text { Honey-thick liquids: liquids thickened to a honey-like }}{\text { consistency }} \\
\text { - } \quad \frac{\text { Pudding-thick liquids: liquids thickened so a spoon can }}{\text { stand alone when placed in the cup }}\end{array}$ \\
\hline
\end{tabular}

Table 2: IDDSI Texture Descriptions adapted from Food Desciptors in www.iddsi.org

\begin{tabular}{|c|c|c|}
\hline Level & Title & Brief descriptiion \\
\hline 0 & Thin & $\begin{array}{l}\text { Flows like water; fast flow; can drink through any type of teat/nipple, cup or straw as appropriate for } \\
\text { age and skills }\end{array}$ \\
\hline 1 & Slightly Thick & $\begin{array}{l}\text { Thicker than water; requires a little more effort to drink than thin liquids; flows through straw, } \\
\text { syringe, teat/nipple; similar to thickness of commercially available "anti-regurgitation" infant formula }\end{array}$ \\
\hline 2 & Mildly Thick & $\begin{array}{l}\text { Flows off a spoon; shippable, pours quickly from a spoon, but slower than thin drinks; effort is } \\
\text { required to drink this thickness through standard bore straw }\end{array}$ \\
\hline 3 & $\begin{array}{l}\text { Moderately Thick } \\
\text { Liquidised }\end{array}$ & $\begin{array}{l}\text { Will hold its shape on a spoon; shippable, pours slowly off a spoon; difficult to suck through a } \\
\text { standard bore or wide bore straw; cannot be piped, layered or molded; cannot be eaten with a fork }\end{array}$ \\
\hline 4 & $\begin{array}{l}\text { Extremely Thick } \\
\text { Pureed }\end{array}$ & $\begin{array}{l}\text { Holds shape on spoon; flows very slowly under gravity; does not required chewing; could be piped, } \\
\text { layered or molded; no lumps; falls off spoon in a single spoonful when tilted to holds its shape on a } \\
\text { plate; cannot be sucked through a straw; not sticky; liquid does not separate from solid }\end{array}$ \\
\hline 5 & Minced \& Moist & $\begin{array}{l}\text { Can be eated with a fork or spoon; could be eaten with chopsticks, in some cases; can be scooped } \\
\text { and shaped; soft and moist with no separate thin liquid; small bumps visible within food; lumps are } \\
\text { easy to squash with tongue }\end{array}$ \\
\hline 6 & Soft & $\begin{array}{l}\text { Can be eaten with a fork, spoon or chopsticks; can be mashed/broken down with pressure from } \\
\text { eating utensil; knife not required to cut this food; soft, tender and moist throughout but with no } \\
\text { separate thin liquid; bite-sized pieces as appropriate for size and oral processing skills }\end{array}$ \\
\hline 7 & Regular & $\begin{array}{l}\text { Normal, everyday foods of various textures; any method may be sued to eat these foods; foods may } \\
\text { be hard and crunchy or naturally soft; includes hard, tough, chewy, fibrous, stringy, dry, crispy, } \\
\text { crunchy or crumbly bits; includes food that contains pips, seeds, pit inside skin, husks or bones }\end{array}$ \\
\hline
\end{tabular}


- $\quad$ Assistance during meals to help remind him/her on safe swallowing strategies (Individuals may not necessarily need diet modifications, rather, reminders to utilize safe swallowing strategies).

- $\quad$ Postural maneuvers such as a chin-tuck strategy (A chin-tuck strategy can improve airway protection) [70].

\section{Direct Neuromuscular Exercises}

Depending on the individual's cognitive ability, (i.e. ability to follow commands), dysphagia treatment may be recommended based on the VFSS findings to improve strength/mobility of oropharyngeal muscles such as:

- $\quad$ Lingual/labial ROM and strengthening exercises

- $\quad$ Laryngeal elevation exercises

- $\quad$ Pharyngeal strengthening exercises

The evidence for the efficacy of common dysphagia exercises are variable [71].

\section{CONCLUDING REMARKS}

As mentioned at the beginning of this paper, persons with ID and feeding/swallowing disorders are severely underserved in this country, and apparently worldwide. Part of the reasoning for this may include the lack of professionals with specialized training in working with this population, reduced funding for research to explore options for improved nutrition and reduced risk of choking and minimal research on changes in feeding skills and/or swallow physiology in persons with ID.

This paper serves as an introduction to healthcare colleagues regarding the risks involved in choking and swallowing disorders in persons with ID, how to evaluate these potential risks and possible treatments. More work needs to be completed to better understand the specific feeding/swallowing patterns prevalent in this heterogeneous population. More work is also needed in identifying specific patterns that may be highlighted during a clinical swallow examination, understanding that sometimes the instrumental examination does not provide the full picture of the individual and his/her problem. This has all been presented in the context of maintaining the best quality of life for each person with ID whom we serve.

\section{REFERENCES}

[1] Patja K. Life expectancy of people with intellectual disability: a 35-year follow-up study. J Intellect Disabil Res 2000; 44(5): 590-9.

http://dx.doi.org/10.1046/j.1365-2788.2000.00280.x

[2] Heikura U, Taanila A, Olsen P, Hartikainen AL, von Wedt L, Jarvelin MR. Temporal changes in incidence and prevalence of intellectual disability between two birth cohorts in northern Finland. Am J Ment Retard 2003; 108(1): 19-31. http://dx.doi.org/10.1352/08958017(2003)108<0019:TCIIAP>2.0.CO;2

[3] Rantakallio P, von Wedt L. Mental retardation and subnormality in a birth cohort of 12,000 children in northern Finland. Am J Ment Retard 1986; 90(4): 380-7.

[4] Katusic SK, Colligan RC, Beard CM, et al. Mental retardation in a birth cohort, 1976-1980, Rochester, Minnesota. Am J Ment Retard 1996; 100(4): 335-44

[5] Maulik PK, Harbour CK. Epidemiology of intellectual disability. In: Stone $\mathrm{JH}$, Blouin $\mathrm{M}$, editors. International Encyclopedia of Rehabilitation. Available from: http://cirrie.buffalo.edu/encyclopedia/en/article/144

[6] Chadwick DD, Jolliffe J. A descriptive investigation of dysphagia in adults with intellectual disabilities. J Intellect Disabil Res 2009; 53(1): 29-43.

http://dx.doi.org/10.1111/j.1365-2788.2008.01115.x

[7] Sheppard JJ. Developmental disability and swallowing disorders in adults. In: Cichero J, Murdoch B, editors. Dysphagia: foundations, theory and practice. Chinchester: John Wiley \& Sons Ltd 2006; p. 299-318.

[8] Hardwick KD. Clinical manifestations of dysphagia in individuals with mental retardation: an exploratory study [dissertation]. [Austin (TX)]: University of Texas at Austin; 1993.

[9] Bittles $\mathrm{AH}$, Bower C, Hussain R, Glasson EJ. The four ages of Down syndrome. Eur J Public Health 2007; 17(2): 221-5. http://dx.doi.org/10.1093/eurpub/ckl103

[10] Arvedson JC. Assessment of pediatric dysphagia and feeding disorders: Clinical and instrumental approaches. Dev Disabil Res Rev 2008; 14(2): 118-27.

http://dx.doi.org/10.1002/ddrr.17

[11] Linscheid P, Seboek D, Nylén ES, Langer I, Schlatter M, Becker KL. In vitro and in vivo calcitonin-1 gene expression in parenchymal cells: a novel product of human adipose tissue. Endocrinology 2003; 144(12): 5578-84. http://dx.doi.org/10.1210/en.2003-0854

[12] Kleim J, Jones T. Principles of experience-dependent neural plasticity: Implications for rehabilitation after brain damage. J Speech Lang Hear Res 2008; 51: S225-39. http://dx.doi.org/10.1044/1092-4388(2008/018)

[13] Morris SE, Klein MD. Pre-feeding skills: A comprehensive resource for mealtime development. $2^{\text {nd }}$ ed. Tucson: Therapy Skill Builders; 2000.

[14] Riquelme LF, Soyfer A, Engelman J, Palma G, Stein L, Chao $J$. Understanding oropharyngeal dysphagia: from hospital to home. Home Health Care Mang Pract 2008; 20(6): 462-73. http://dx.doi.org/10.1177/1084822308318178

[15] Leder SB. Gag reflex and dysphagia. Head Neck 1996; 18(2): 138-41.

http://dx.doi.org/10.1002/(SICI)10970347(199603/04)18:2<138::AID-HED 5>3.0.CO;2-2

[16] Leder SB. Videofluoroscopic evaluation of aspiration with visual examination of the gag reflex and velar movement. Dysphagia 1997; 12(1): 21-3. http://dx.doi.org/10.1007/PL00009514

[17] Calis EA, Veugelers R, Sheppard JJ, Tibboel D, Evenhuis $\mathrm{HM}$, Penning C. Dysphagia in children with severe 
generalized cerebral palsy and intellectual disability. Dev Med Child Neurol 2008; 50(8): 625-30.

http://dx.doi.org/10.1111/j.1469-8749.2008.03047.x

[18] Logemann JA, Veis S, Colangelo L. A screening procedure for oropharyngeal dysphagia. Dysphagia 1999; 14(1): 44-51. http://dx.doi.org/10.1007/PL00009583

[19] Marik PE. Aspiration pneumonitis and aspiration pneumonia. N Eng J Med 2001; 344(9): 665-71.

http://dx.doi.org/10.1056/NEJM200103013440908

[20] Langmore SE, Terpenning MS, Schork A, et al. Predictors of aspiration pneumonia: how important is dysphagia? Dysphagia 1998; 13(2): 69-81. N Engl J Med 2001; 344(9): 665-71.

[21] Huxley EJ, Viroslav J, Gray WR, Pierce AK. Pharyngeal aspiration in normal adults and patients with depressed consciousness. Am J Med 1978; 64(4): 564-8. http://dx.doi.org/10.1016/0002-9343(78)90574-0

[22] Gleeson K, Eggli DF, Maxwell SL. Quantitative aspiration during sleep in normal subjects. Chest 1997; 111(5): 126672.

\section{http://dx.doi.org/10.1378/chest.111.5.1266}

[23] Marik PE, Kaplan D. Aspiration pneumonia and dysphagia in the elderly. Chest 2003; 124(1): 328-36.

http://dx.doi.org/10.1378/chest.124.1.328

[24] Zimmer JG, Bently DW, Valenti WM, Watson NM. Systemic antibiotic use in nursing homes. A quality assessment. J Am Geriatr Soc 1986; 34(10): 703-10.

http://dx.doi.org/10.1111//.1532-5415.1986.tb04301.x

[25] Crossley KB, Thurn JR. Nursing home-acquired pneumonia. Semin Respir Infect 1989; 4(1): 64-72.

[26] Pugliese G, Lichtenberg DA. Nosocomial bacterial pneumonia: an overview. Am J Infect Control 1987; 15(6): 249-65.

http://dx.doi.org/10.1016/0196-6553(87)90119-2

[27] Kaplan V, Angus DC, Griffin MF, Clermont G, Scott Watson R, Linde-Zwirble WT. Hospitalized community-acquired pneumonia in the elderly: age- and sex-releated patterns of care and outcome in the United States. Am J Respir Crit Care Med 2002; 165(6): 766-72.

http://dx.doi.org/10.1164/ajrccm.165.6.2103038

[28] Jokinen $\mathrm{C}$, Heiskanen L, Juvonen $\mathrm{H}$, et al. Incidence of community-acquired pneumonia in the population of four municipalities in eastern Finland. Am J Epidemiol 1993; 137(9): 977-88.

[29] Koivula I, Sten M, Mäkelä PH. Risk factors for pneumonia in the elderly. Am J Med 1994; 96(4): 313-20. http://dx.doi.org/10.1016/0002-9343(94)90060-4

[30] Loeb M, Mcgreer A, McArthur M, Walter S, Simor AE. Risk factors for pneumonia and other lower respiratory tract infections in elderly residents of long-term care facilities. Arch Intern Med 1999; 159(17): 2058-64. http://dx.doi.org/10.1001/archinte.159.17.2058

[31] May ME, Kennedy $\mathrm{CH}$. Health and problem behavior among people with intellectual disabilities. Behav Anal Pract 2010; 3(2): 4-12.

[32] Malcom A, Thumshirn MB, Camilleri M, Williams DE. Rumination Syndrome. Mayo Clin Proc 1997; 72(7): 646-52. http://dx.doi.org/10.1016/S0025-6196(11)63571-4

[33] Stortz JN, Lake JK, Cobigo V, Ouellette-Kuntz HM, Lunsky Y. Lessons learned from our elders: how to study polypharmacy in populations with intellectual and developmental disabilities. Intellect Dev Disabil 2014; 52(1): 60-77. http://dx.doi.org/10.1352/1934-9556-52.1.60

[34] Bjerrum L, Rosholm JU, Hallas J, Kragstrup J. Methods for estimating the occurrence of polypharmacy by means of a prescription database. Eur J Clin Pharmacol 1997; 53(1): 711.

http://dx.doi.org/10.1007/s002280050329
[35]

Chutka DS, Takahashi PY, Hoel RW. Inappropriate medications for elderly patients. Mayo Clin Proc 2004; 79(1): 122-39. http://dx.doi.org/10.4065/79.1.122

[36] Straetmans JMJAA, Van Schrojenstein Lantman-de Valk HM, Schellevis FG, Dinant GJ. Health problems of people with intellectual disabilities: the impact for general practice. $\mathrm{Br} J$ Gen Pract 2007; 57(534): 64-6.

[37] Bisconer SW, Sine LF, Zhang X. Prevalence and patterns of psychotropic medication use by adults with mental retardation living in community settings. J Dev Phys Disabil 1996; 8(4): 291-311. http://dx.doi.org/10.1007/BF02578397

[38] Burd L, Williams M, Klug MG, Fjelstad K, Schimke A, Kerbeshian J. Prevalence of psychotropic and anticonvulsant drug use among North Dakota group home residents. J Intellect Disabil Res 1997; 41(6): 488-94.

http://dx.doi.org/10.1111/j.1365-2788.1997.tb00741.x

[39] Lake JK, Balogh R, Lunsky Y. Polypharmacy profiles and predictors among adults with autism spectrum disorders. Res Autism Spectr Disord 2012; 6(3): 1142-9. http://dx.doi.org/10.1016/j.rasd.2012.03.005

[40] Lott IT, McGregor M, Engelman L, et al. Longitudinal prescribing patterns for psychoactive medications in community-based individuals with developmental disabilities: utilization of pharmacy records. J Intellect Disabil Res 2004; 48(6): 563-71.

http://dx.doi.org/10.1111/j.1365-2788.2004.00625.x

[41] Lunksy $\mathrm{Y}$, Elserafi J. Antipsychotic medication prescription patterns in adults with developmental disabilities who have experienced psychiatric crisis. Res Dev Disabil 2012; 33(1): 32-8. http://dx.doi.org/10.1016/j.ridd.2011.08.003

[42] Marshall T. Audit of the use of psychotropic medication for challenging behaviour in a community learning disability service. BJPsych Bull 2004; 28(12): 447-50.

http://dx.doi.org/10.1192/pb.28.12.447

[43] McGillivray JA, McCabe MP. Emerging trends in the use of drugs to manage the challenging behaviour of people with intellectual disability. J Appl Res Intellect Disabil 2006; 19(2): 163-72.

http://dx.doi.org/10.1111/j.1468-3148.2005.00251.x

[44] Stolker JJ, Heerdink ER, Leufkens HG, Clerkx MG, Nolen WA. Determinants of multiple psychotropic drug use in patients with mild intellectual disabilities or borderline intellectual functioning and psychiatric or behavior disorder. Gen Hosp Psychiatry 2001; 23(6): 345-9. http://dx.doi.org/10.1016/S0163-8343(01)00164-5

[45] Wood D, Hall AG, Zhang J, Hou T. Predictors of psychoactive medication use by persons on the MR/DD home and community based waiver. Florida: Univ of Florida. 2006.

[46] Aman MG, Benson BA, Campbell KM, Haas BA. Patients rights and responsibilities. Columbus: The Ohio State University Nisonger Center, 1999. Available from: http://nisonger.osu.edu/media/projectmed/Project_MED_Boo klet_1_Patients_Rights.pdf

[47] Bradley E. Guidelines for managing the client with intellectual disability in the emergency room. Toronto: Centre for Addiction and Mental Health; 2002.

[48] Gardner Wilson J, Lott RS, Tsai L. Side effects: recognition, and management. In: Aman MG, Reiss S, editors. Psychotropic medications and developmental disabilities: the international consensus handbook. Columbus: Ohio State University 1998; p. 95-114.

[49] Lunksy $Y$, Fedoroff $P$, Klassen $K$, et al. Medical rights for people with intellectual disabilities. In: Owen F, Griffiths G, editors. Challenges to the human rights of people with intellectual disabilities. Philadelphia: Jessica Kingsley Publishers 2008; p. 155-83. 
[50] Zamertkin AJ, Yamada EM. Monitoring and measuring drug effects. In: Werry JS, Aman MG, editors. Practitioner's guide to psychoactive drugs for children and adolescents. New York: Plenum Press 1993; p. 86-91.

http://dx.doi.org/10.1007/978-1-4615-2884-5 4

[51] Ananth J, Parameswaran S, Gunatilake S. Antipsychotic polypharmacy. Curr Pharm Des 2004; 10(18): 2231-8. http://dx.doi.org/10.2174/1381612043384033

[52] Fulton M, Allen ER. Polypharmacy in the elderly: a literature review. J Am Acad Nurse Pract 2005; 17(4): 123-32. http://dx.doi.org/10.1111/j.1041-2972.2005.0020.x

[53] Jyrkkä J, Enlund H, Korhonen MJ, Sulkava R, Hartikainen S. Patterns of drug use and factors associated with polypharmacy and excessive polypharmacy in elderly persons: results of the Kuopio 75+ study: a cross-sectional analysis. Drugs Aging 2009; 26(6): 493-503.

http://dx.doi.org/10.2165/00002512-200926060-00006

[54] Flaherty JH, Perry HM $3^{\text {rd }}$, Lynchard GS, Morley JE. Polypharmacy and hospitalization among older home care patients. J Gerontol A Biol Sci Med Sci 2000; 55(10): M5549.

http://dx.doi.org/10.1093/gerona/55.10.M554

[55] Ziere G, Dieleman JP, Hofman A, Pols HA, van der Cammen $\mathrm{TJ}$, Stricker $\mathrm{BH}$. Polypharmacy and falls in the middle age and elderly population. Br J Clin Pharmacol 2005; 61(2): 21823.

http://dx.doi.org/10.1111/j.1365-2125.2005.02543.x

[56] Eady N, Courtenay K, Strydom A. Pharmacological management of behavioral and psychiatric symptoms in older adults with intellectual disability. Drugs Aging 2015; 32(2): 95-102.

http://dx.doi.org/10.1007/s40266-014-0236-7

[57] Balzer KM. Drug-induced dysphagia. Intl J MS Care 2000; 2(1): 40-50. http://dx.doi.org/10.7224/1537-2073-2.1.40

[58] Molyneux P, Emerson E, Caine A. Prescription of psychotropic medications to people with intellectual disabilities in primary health care settings. J Appl Res Intellect Disabil 1999; 12(1): 46-57. http://dx.doi.org/10.1111/j.1468-3148.1999.tb00049.x

[59] National Core Indicators. What does $\mathrm{NCl}$ tell us about adults with intellectual and developmental disabilities who are taking prescribed medications for anxiety, behaviour challenges, mood disorders or psychotic disorders? $\mathrm{NCl}$ data brief, no 6; 2012.

[60] Spreat S, Conroy JW, Fullerton A. Statewide longitudinal survey of psychotropic medication use for persons with mental retardation: 1994 to 2000. Am J Ment Retard 2004; 109(4): 322-31.

http://dx.doi.org/10.1352/0895$\underline{8017(2004) 109<322: \text { SLSOPM }>2.0 . C O ; 2}$
[61] Humbert IA, Robbins J. Dysphagia in the elderly. Phys Med Rehabil Clin N Am 2008; 19(4): 853-66. http://dx.doi.org/10.1016/j.pmr.2008.06.002

[62] Carnaby G. Food for thought: importance of a clinical exam/cranial nerve assessment. Perspect Swal Swal Dis (Dysph) 2012; 21(4): 143-9. http://dx.doi.org/10.1044/sasd21.4.143

[63] McCullough GH, Wertz RT, Rosenbek JC. Sensitivity and specificity of clinical/bedside examination signs for detecting aspiration in adults subsequent to stroke. J Commun Disord 2001; 34(1-2): 55-72.

http://dx.doi.org/10.1016/S0021-9924(00)00041-1

[64] Riquelme LF. Clinical swallow examination (CSE): can we talk? Perspect Swal Swal Dis (Dysph) 2015; 24(1): 34-39. http://dx.doi.org/10.1044/sasd24.1.34

[65] Mathers-Schmidt BA, Kurlinski M. Dysphagia evaluation practices: inconsistencies in clinical assessment and instrumental examination decision-making. Dysphagia 2003; 18(2): 114-25.

http://dx.doi.org/10.1007/s00455-002-0094-z

[66] Coyle JL. The clinical evaluation: a necessary tool for the dysphagia sleuth. Perspect Swal Swal Dis (Dysph) 2015; 24(1): 18-25.

http://dx.doi.org/10.1044/sasd24.1.18

[67] Patel R, Hillier R. Primary refusal to eat in people with moderate intellectual disability-mirtazapine used successfully to restore appetite. Eur Psychiatry 2013; 28(1): 1. http://dx.doi.org/10.1016/S0924-9338(13)75767-5

[68] Cichero JA, Steele C, Duivestein J, et al. The need for international terminology and definitions for texture-modified foods and thickened liquids used in dysphagia management: foundations of a global initiative. Curr Phys Med Rehabil Rep 2013; 1(4): 280-91.

http://dx.doi.org/10.1007/s40141-013-0024-z

[69] Butler S, Stuart A, Leng LX, Rees C, Williamson J, Kritchevsky SB. Factors influencing aspiration during swallowing in health older adults. Laryngoscope 2010; 120(11): 2147-52.

http://dx.doi.org/10.1002/lary.21116

[70] Fraser S, Steele C. The effect of chin down position on penetration-aspiration in adults with dysphagia. Canadian Journal of Speech-Language Pathology and Audiology; 36(2): 142-8.

[71] Langmore SE, Pisegna JM. Efficacy of exercises to rehabilitate dysphagia: a critique of the literature. Int $\mathrm{J}$ Speech Lang Pathol 2015; 17(3): 222-9. http://dx.doi.org/10.3109/17549507.2015.1024171

\section{DOI: http://dx.doi.org/10.6000/2292-2598.2016.04.02.2}

(C) 2016 Riquelme et al.; Licensee Lifescience Global.

This is an open access article licensed under the terms of the Creative Commons Attribution Non-Commercial License (http://creativecommons.org/licenses/by-nc/3.0/) which permits unrestricted, non-commercial use, distribution and reproduction in any medium, provided the work is properly cited. 